\title{
Reliability and Adaptability of Religious Beliefs in the Light of Cognitive Science of Religion
}

\section{Konrad Szocik}

University of Information Technology

and Management in Rzeszow,

Poland

e-mail: kszocik@wsiz.rzeszow.pl

\begin{abstract}
:
Cognitive approach towards the study of religion is a good and promising way. However, I think that this approach is too narrow and it would be better to use some basic concepts of CSR as a starting point for further, not cognitive explanation of religious. I suppose that religious beliefs should be explained also by their pragmatic functions because they were probably always associated with some pragmatic purposes at the group or at the individual levels. To develop further this last approach, the good explanatory way is the evolutionary study of religion.

Keywords: cognitive science of religion, evolutionary science of religion, byproduct, adaptation.
\end{abstract}

Whereas the ease with which humans acquire fear of snakes presumably evolved in response to snakes themselves as a survival threat, the ease with which humans acquire belief in gods is not thought to have evolved in response to gods [4].

\section{Introduction}

Cognitive science is a research method for looking at behavior or beliefs. Cognitive Science of Religion (CSR) is not a singular entity. CSR has many different points of view, probably as many as there are people that use cognitive scientific methods to conduct their investigations. I am aware of this complexity when I use the general term 'Cognitive Science of Religion.' I will discuss some concepts and explanations developed within CSR and I will refer to the evolutionary study of religion and religious beliefs.

As one might expect given the name of the field, CSR purports that religious beliefs are cognitively natural [6]. 'Naturalness' as it is used in CSR generally bears a favorable implication for the concept it describes. If a concept is natural, it may imply pragmatism, epistemic reliability, and intuitive acquisition. However, naturalness may also undermine justification and reliability of a concept by explaining it away as a by-product of evolution or as an adaptation evolved by natural selection. Thus there is a tension involved when a concept is deemed natural or not. Typically, CSR 
describes religious beliefs as natural and intuitive with agnosticism toward the reliability of religious beliefs to describe reality. In contrast, the non-natural ideas like those that belong to science are far more reliable. This idea is epitomized in the words of Robert McCauley who argues that "religion is natural and science is not" [21]. Thus naturalness develops a negative implication for ontological veracity in CSR. This topic can be connected with evolutionary debunking arguments that state that the evolutionary origin of a given belief raise questions about its truthfulness and justification.

While CSR bears many useful and important insights concerning the development and use of religious beliefs, CSR is not justified in describing religious beliefs as natural in all the ways, including in intuitiveness, adaptability, and unreliability. What is more, it is not clear that the descriptor of 'naturalness' undermines a concept's reliability. Factors beyond the scope of CSR must be considered to conduct such an evaluation.

In this paper I argue that religious beliefs:

1. are a function of past adaptability rather than current adaptability. However, this topic evolutionary explanation of religious beliefs in terms of survival and reproduction - is very complex and complicated and it depends on the way adaptation is interpreted (when one uses a strict or broad definition of adaptation). Jay Feierman discusses in a detailed way one of the possible biological approaches to religion looking for religious roots of evolution of eusociality (Jay Feierman's paper in this issue) [13],

2. never were reliable and cannot be evaluated in epistemic terms,

3. may be understood as natural only in their particular environmental contexts (Hans Van Eyghen's paper in this issue is focused on topics of naturalness and trustworthiness of religious beliefs) [11],

4. are not intuitive because they cannot be any kind of intuition,

5. function uniquely as adaptive traits.

It seems that religious/theistic intuitions do not exist because they work on other non-religious intuitions. Some scholars like Helen de Cruz and Joseph de Smedt suggest that human beings can have some religious or even theological intuitions based on the so-called design stance or a theological approach that can be interpreted as theological or co-opted with religious contents [9]. However, I mean evolutionary debunking argument that suggests that intuitions have evolved in the past environment and religious beliefs never were intuitions evolved by natural selection as specially designed for religious contents [7]. Consequently, it becomes evident that these CSR interpretations of religious beliefs that explain them as by-products or side effects of natural selection are fundamentally flawed. I think that the CSR approach gives only proximate, not ultimate explanations of the origin and acquisition of religious beliefs. In this sense it could be said that every human belief is a by-product of natural cognition because cognition itself was not specially designed for any cultural contents. However, I suggest that naturalness of religion hypothesis describes technical work of human cognition when it meets religious contents. This approach does not say anything about their evolutionary, functional origin. I assume that reference to the pragmatic contexts of religious beliefs may radically change the meaning of their naturalness.

\section{Religious Beliefs and Intuitions}

CSR generally assumes that religious beliefs are intuitive and counterintuitive; intuitive in the sense of their acquisition and transmission but counterintuitive in the sense of their content, which often breaks intuitive expectations of ontology [2], [3]. In this understanding, a quandary arises: intuitively acquired beliefs that are counterintuitive in content may contradict other intuitively acquired beliefs. And yet, CSR scholars like Pascal Boyer, Justin Barrett, or McCauley contend that such ontologically counterintuitive beliefs remain intuitive in regard to their acquisition. But if an intuitively acquired belief can contradict another intuitively acquired belief, then it seems the significance of defining a belief as intuitive is limited to meaning that it is simple but without any 
relevance to reliability. Such a restriction throws into doubt the claim that religious beliefs are intuitive at all, either in content or in acquisition.

Intuitive acquisition as it is understood here describes ideas (called intuitions) obtained in a fast, direct, and unreflective way. But perhaps it would be better to distinguish between the acquisition of intuitions and the appearance of intuition. It is assumed that intuitions or ideas interpreted as intuitive have long evolutionary histories [9]. Selective pressures appropriate for one particular environment have affected particular ways of thinking and interpretations of the world. Consequently, the most adaptive kinds of behavior have endured. In this place it is worth making a distinction between two levels: non- or a-religious intuitions that are a cognitive base for religious contents, and religious and theistic intuitions. CSR assumes that human beings have some basic cognitive mechanisms and processes which work in intuitive and spontaneous ways [2]. They do not have religious and any other cultural content. On the other hand, we can ask whether there are some possible religious or theistic intuitions that are intuitive in the sense described above. It seems that in this case we should say rather about culturally contaminated intuitions. We can find some approaches that suggest that human beings, especially children are intuitive theists [16], [18], [19], [26]. However, in this matter it is worth bearing in mind a difference between strictly religious or theistic nature of intuition and its cultural contamination which can cause that in some cultural conditions religious reference seems to be more natural and intuitive than atheistic or non-religious. In the light of recent discoveries that suggest that basic emotional reactions are not universal for the entire humankind [8], we can doubt if such specific beliefs like supernatural ones can be rooted in any universal religious/supernatural intuitions.

Intuitions that work in the current environment usually were evolved in the past. They could be adaptive in the past environment when we assume that selective pressure has been looking for adaptive strategies. There is only one of the possible explanations because a feature that has particular function can be a result of by-product of other adaptation, the result of phylogenetic history, or the product of genetic drift [14], [15]. Let us assume this first explanation that states that intuitions could be adaptations at least in the past environment. We can assume, like Kelly James Clark notes, that these intuitions are not reliable. Perhaps their main purpose is usefulness and adaptability, not reliability. Clark notes that these intuitions theoretically could be truth-tracking in that past environment but in the current world they may be unreliable [7, p. 1]. This point of view is one of the crucial elements of the main idea of CSR supported by many scholars within CSR that religious beliefs are the by-product of natural cognition. Religious beliefs are not evaluated epistemically in terms of truth and falsity within CSR. However, they are not evaluated also pragmatically in the evolutionary terms of survival and reproduction [24, p. 243]. It appears that the cognitive scientific approach excludes both epistemic and pragmatic kinds of analysis of religious beliefs. In this paper I suggest that religious beliefs should be interpreted in an adaptive way and it is worth bearing in mind their alleged usefulness - today or at least in the past.

Looking for an evolutionary history of current intuitions may function as a kind of evolutionary debunking argument. The core idea of this kind of argument assumes that the explanation of an evolutionary origin of a given feature leads to undermine its justification and reliability. In other words we can say, like Guy Kahane, that the "aetiology of a belief can undermine its epistemic standing" [17, pp. 103, 105]. Religious intuitions (if we can say about these kinds of intuitions) have a secondary nature because they are strictly connected with evolutionarily prior intuitive mechanisms that are blind in the sense of their contents. In this context we agree with the main paradigm of CSR that religious beliefs are affected by automatic natural cognitive mechanisms like some kind of agency detection or a design stance. However, we treat these cognitive modules like proximate, not ultimate causes for acquisition and transmission of religious beliefs. Concerning evolutionary debunking argument we can say that this evolutionary perspective undermines the reliability of religious beliefs because human beings probably do not have any specific mechanisms that have evolved for religious purposes. We find that in the case of moral matters we could try to look for evolutionary mechanisms that where specially designed for moral purposes. We mean moral emotions or evolutionarily deeply rooted "tit for tat's" rule that is the 
basis for selfish and altruistic behaviors as well [31], [34], [36]. However, we do not find any similar mechanism that could have evolved for religious contents. This is why we can accept evolutionary debunking arguments within the framework of religious beliefs. Consequently, this point of view excludes the possibility of looking for epistemic value in religious beliefs.

It seems that so called religious or theistic intuitions are based on other non-religious intuitions that also can be maladaptive in the current environment. This issue is a part of the debate between adaptations and by-products as well as traits that have lost their adaptive functions [28].

\section{Naturalness of Religious Beliefs}

The question of the naturalness of religious beliefs and religion was discussed in another paper in reference to the question of the naturalness of atheism in the sense of ultimate explanation [33]. Here we would like to briefly recall the possible basic meanings of the term naturalness in the context of religious beliefs. In light of CSR, religious beliefs are explained as natural ones because they are non-supernatural in the sense of proximate explanation. This point can be a starting point for all ideological interpretations of CSR. For example, the naturalness of religion hypothesis in the sense of its non-supernatural nature may be interpreted as an argument for an atheistic worldview. However, this claim refers rather to proximate, not ultimate mechanisms and shows that religious beliefs work on the basis of natural cognitive mechanisms. This proximate explanation excludes theistic and atheistic ways of interpreting the naturalness of religion hypothesis.

Another meaning of "naturalness" focuses on the intuitive nature of religious beliefs. In this context we assume that a feature or a trait that is intuitive and in some sense automatically or spontaneously acquired or perceived, is natural. Here we have to refer to McCauley's distinction between maturational and practical naturalness [21]. However, it is worth bearing in mind that the intuitive nature of a given trait is context-dependent. It refers to many different traits like morality, culture, religion, etc. Consequently, we can interpret many different traits and features as intuitive. We only should underline what type of origin - innate or culturally acquired - we mean. Of course, the amount of innate traits is very limited. We can assume that some religious forms will be interpreted as intuitive because they are culturally dominant and in a particular cultural context they will be a "natural" starting point. It is similar to "the Baldwin effect" when a feature or behavior that is useful is acquired by, for example, imitation, and then is culturally inherited from one generation to another. Finally, this behavior could become our "second nature" and in some sense it can function as an intuition [15].

The third meaning is strictly associated with the latter one and it refers to a trait that is cognitively effortless. This feature refers to the way of acquisition of a trait. Religious beliefs within CSR are understood as natural also in this sense. However, consider the following virtual comparison between religious and atheistic beliefs (or, perhaps it would be better to say about a lack of religious beliefs). It is not clear whether we can separate these two kinds of beliefs according to the level of intuitiveness and cognitive easiness. In this case we should compare plasticity of individual imaginations and an ability to accept competitive worldviews. It seems that it is not easy to strictly separate a domain of natural cognition from a domain of cultural and educational training [20]. We suggest that the religious point of view can be interpreted as more natural in the sense of intuitiveness and cognitive easiness because it is a result of cultural training and it is a core element of given cultural environment. Analogically, an atheist or non-believer probably in the same way would have some troubles in acceptance religious understanding of the world. Consequently, we find that demarcation line lies in cultural context, not in specific nature of natural human cognition.

We prefer to explain the universality of religious beliefs via the concept of convergent evolution rather than by the concept of the same cognitive background. We mean similarity by analogy when the same feature has evolved by the same or very similar pressure in different and independent lineages [14]. We treat cognition like a secondary feature. We suggest that religious beliefs are universal because they were favored by natural selection for achieving the same 
psychological and social purposes. In this sense, their occurrence is casual. It seems that cognitive explanation of origin and transmission of religious beliefs should lead to their necessary validity. However, we know that they are not obligatory human features and that even religious people do not treat consistently their beliefs. In this sense we conclude that cognitively affected religious beliefs should be more deeply rooted in the human mind. It is obvious that their impact is not so great. This is why we suggest that their origin is rooted in their evolutionary adaptive nature. This adaptive nature can explain why these beliefs sometimes can strongly affect human decisions and actions, and why sometimes they do not. We suppose that this difference is caused by an individual and group opportunity of reference to different biological or cultural tools that could serve as tools for solving problems. This choice is very context-dependent. For example, an individual or a group can choose this feature that is or that seems to be more efficient or less costly. We mean especially the rational choice theory of Rodney Stark. He finds that believer can reject religious point of view or rather religious way of solving problem when he sees that other solutions that are more efficient or less costly are available [29]. Of course, cultural religious training can have great impact for individual or group enhancement of religious point of view.

We can find also the fourth meaning of naturalness of religion and religious beliefs. Naturalness may mean something that is evolved by natural selection. In this sense that is difficult to strictly demarcate adaptation and by-product. It seems that this question is a matter of concepts and definitions. We can find several features that should be done by a trait that is called an adaptation. Let us in the following paragraph refer to this fourth meaning of naturalness and mention these features and let us consider whether religious beliefs could meet these criteria.

\section{The Fourth Meaning of Naturalness of Religious Beliefs}

Adaptation can be a trait that is genetically inherited. This narrow definition would exclude religious beliefs because there are no genes directly associated with religious phenomena. However, a broad definition of adaptation not only allows for epigenetic inheritance of adaptation but also suggests that adaptation does not have to be inherited [12], [35]. We can imagine a situation when someone has adaptation but he does not reproduce. We do not doubt that religious beliefs can be inherited only via culture and education.

Another feature required for adaptation is being a product of the historic process of selection. It seems that religious beliefs fit this criterion. For instance, we find historical records for Christian beliefs first in the Gospels. Then we find their further historical development. We know that religious beliefs have evolved and they were the subject of controversies and arbitrary decisions, like in the case of councils in the institutional Christianity. In this context we can say that these beliefs were a matter of historical selection. Selection in historical process makes pressure for seeking the most adaptive and useful traits. In this sense perhaps it would be possible to explain at least some beliefs as a result of historic process of selection. We mean especially the oldest kind of beliefs like the concept of an afterlife or shamanism [23].

Adaptation should be specially designed by natural selection for the purpose of a particular function. This function should be adaptive in the current environment or at least in the past. It is not important whether religious beliefs or rituals are the current adaptations or whether they are maladaptive today but they were adaptive in the past. This question also depends on a given theoretical approach. We can take a perspective that excludes the possibility of interpreting cultural phenomena in the terms of adaptations evolved by natural selection. However, we accept this possibility and we assume that some religious beliefs and behaviors as well as religions could be interpreted as features specially designed by natural selection. We take an approach developed by David Sloan Wilson who claims that religious faith can be understood as an adaptation when it affects group behaviors that turns this group into adaptive unit [36]. We mean "specially designed" by natural selection like a process in which natural selection promotes development of - in this case - these cultural traits that are adaptive in the terms of survival and reproduction. In this sense we can evaluate religious beliefs as specially designed by natural selection if they are useful in 
evolutionary sense. We can go a step further and assume that cultural evolution is affected by sexual selection and in the field of ultimate explanation perhaps all or at least many different cultural phenomena have evolved because supposed direct or indirect attractiveness for mate. Males who have better access to resources can be more attractive for females who can think resources necessary for survival of her offspring. We can interpret as adaptations all mechanisms that increase the amount of material resources [14].

Another feature of adaptation is an ability to produce individual benefits. That is unquestionable feature of many religious beliefs and practices that they are very useful. We know about the phenomenon of religious coping. We find that first religious beliefs and practices probably were associated with a positive impact on health. Societal impact was also very important but probably is much younger component of religious beliefs and religion in their history. We suggest that this feature of adaptation is fully met by religious beliefs and practices today and in the past. Of course, this adaptive component has changed over time and some beneficial parts of religious beliefs and practices could lose their beneficial nature. We mean, for example, that the process of secularization may be a critical factor in which religious beliefs can lose their positive power. However, it seems that this component of religious beliefs is in general rather independent of historical and cultural changes. A believer who shares some religious beliefs can receive profits from his religious practices especially in the psychological sense [27]. Another field where this criterion is commonly realized is the life of clergy. In many religions clergy is the social cast that has specific laws and has privileged access to resources.

Finally, we find fitness maximization as a very important feature of adaptation. Religious beliefs and religion can efficiently meet this criterion. We know correlation between high level of religiosity and high level of fertility and reproduction [5]. Perhaps this correlation is a stable feature when the level of religiosity is enough high. In secularized Western Europe Christian beliefs have lost their adaptive nature in this sense as a group level adaptation which motivates to reproduction. In the past, religious beliefs in this part of world were efficient cultural tool that motivate to high level of reproduction [36]. Despite loss of real impact, institutionalized Christianity, especially the Roman Catholic Church until today is focused in its social and cultural policy on sexual matter connected with the question of reproduction. This approach is especially developed in Poland where the Church has fighted against proclamation of "The Council of Europe Convention on preventing and combating violence against women and domestic violence" [32]. When we are brought up in the cultural framework after the Second World War in which human rights and the concept of equality are natural starting points we can be a bit surprised and confused that the Church in Poland was (and perhaps still is until today) against this law. However, it is possible to find rational motivation for this statement when we refer to the subordinated role played by women whose main purposes in this framework is reproduction and the care of offspring. In this sense, the catholic approach is even more radical than hunter-gatherer communities living in the Pleistocene. Among hunter-gatherer groups women could and had to look for food [10]. In the catholic tradition, women could only cook this food, but not look for them outside households.

\section{Adaptability of Religious Beliefs}

We suggest that the main purpose and cause of the existence and persistence of religious beliefs and religion were their adaptive functions. In the history of religion we find that probably psychological functions were chronologically first. Peoples et al. find that among communities of hunter-gatherers the most popular kind of belief is animism. Then we find belief in an afterlife and shamanism [23]. We can suppose that these kinds of beliefs had and can have in the current societies psychological functions. This question of religious coping underlines the adaptive nature of religious and supernatural beliefs that had and have positive impact on psychical and physical health. It seems to be obvious that these beliefs had to be adaptive in the terms of survival and reproduction. Different situations when these kinds of beliefs could occur seem to be too far from evolutionary rationality that favors the simplest and the least costly mechanisms and solutions. Religion can't be an 
adaptation because it is too broad and heterogeneous to be a structural design feature. However, beliefs in general and religious beliefs in particular, because they are made of information, are physical structural design features and can be culturally transmitted adaptations when adaptation is defined in the broad sense [12].

If we assume that religious and supernatural beliefs are rather cost in the sense of energy and time because they direct attention to non-real objects, we would find the great evolutionary or genetic fallacy when natural selection could enable emergence of these kinds of non-real beliefs. This is why we suggest that they had to be pragmatic. In this sense we assume that the CSR approach is not right when it is focused on the by-product and casual nature of religious beliefs that have occurred "spontaneously" because they were casually favored by natural cognition, especially agency detection device. This explanation seems improbable from the evolutionary point of view. In this context we suggest that - especially in the light of mentioned above research of Peoples et al. - religious/supernatural beliefs have emerged for pragmatic, psychological purposes. We mentioned animism, the concept of an afterlife and shamanism. Then, especially after the Agricultural Revolution, we find the dead ancestor worship and high moralizing gods/God worship. In this period of human evolution we can find new social problems which were not known for small hunter-gatherers societies. This new level of human organization - large groups of unrelated individuals - has caused new social and ethical problems [30]. These problems probably could not be solved by natural biological mechanisms. However, we can refer to the concept of WynneEdwards who suggests that group selection leads to group adaptations. We find on the other side George Williams' approach that rejects the idea of group selection. Williams states that individual selection that favors selfishness is a more powerful mechanisms because individual changes occurs much frequent than changes at the group level [14]. Natural selection has looked for new solutions like cultural tools. One of them was mentioned in two kinds of worships (ancestors and then gods/God). These supernatural observers theoretically were good candidates for social disciplinary tools [22].

To sum up we suppose that CSR, especially the first standard model fails because it underestimates the pragmatic usefulness of religious/supernatural beliefs and overestimates the role played by natural cognitive mechanisms whose nature could be attractive for the occurrence of these beliefs. We claim that natural selection in some sense specially has designed these beliefs to enable solution of first psychological, and then social problems. In the natural history of human beings these prior psychological functions have work all time and today we can find that psychological usefulness of religious beliefs is probably their main function. It is possible to state that religious beliefs in this context are not adaptations but exaptations. We can observe that in the secularized West religious beliefs also today work as adaptive trait but rather in psychological than social sense. We can find examples of religious groups that probably work as adaptive groups until today [36]. This topic suggests that religious beliefs cannot be interpreted nor in cognitive nor in epistemic terms. Cognitive explanation does not introduce anything new because natural cognition is normal and basic ground for other kinds of beliefs. When we take the CSR approach we should assume that all adaptations are by-product because they always use other mechanisms and elements that were not designed for a given feature.

\section{Reliability of Religious Beliefs and Factual Versus Pragmatic Realism}

CSR rather excludes an opportunity to interpret religious beliefs in epistemic terms of truth and falsity. It seems that this question is beyond its focus for at least two reasons. First, CSR presents a functional approach and explains rather than justifies the work of cognitive mechanisms. Second, cognitive mechanisms are interpreted in evolutionary terms of increasing chances for survival. In this sense, they are not understood as truth-tracking but as fitness maximization oriented [9]. From this point of view the reliability of natural cognition is not very important.

At the basic level of survival and reproduction natural cognition should work in a reliable way because we need to have an efficient system for defense and for looking for food. Reliable 
interpretation of the external world usually can be required to achieve these purposes. However, at the higher level of social organization we can find in the human history that our natural cognition was not truth-oriented. Human beings have created different fictive belief systems that were focused on pragmatism rather than truth. Effective religious system does not have to be reliable. We find some basic concepts like, for instance, eight rules of big gods that probably have worked effectively independently on their reliability [22].

This topic is a domain of a difference between factual and pragmatic realism. Religious beliefs like many other belief systems are a domain of this latter one. Perhaps science is the only unique belief system that is fully truth-oriented [36]. How in this context can we interpret the cognitive approach to religious beliefs that are explained as a by-product or side-effect? Our approach is as follows. On the one side, we accept this point because in the sense of proximate explanation natural human cognition is not religiously oriented. Religious beliefs perhaps work and react better and faster with these cognitive mechanisms than other kinds of beliefs. Perhaps their contents make them better candidate for parasitizing on cognition than other beliefs. We mean agency detection, Theory of Mind, or anthropomorphic inclinations of human cognition.

On the other side, we think that this interaction with natural cognitive mechanisms does not matter because cognition is a natural and necessary starting point for all kinds of beliefs. Even if religious beliefs are better candidates for global transmission than others we suggest that their universal presence is a domain of convergent evolution and adaptive usefulness for solving psychological and social problems. As we said earlier, we suppose that it seems to be improbable that such a costly energetically system could spontaneously evolved as a non-controlled by natural selection its by-product.

\section{What For Do We Need a By-product?}

We assume that religious beliefs are not by-products in functional sense. We suggest that natural selection in some sense specially designed these kinds of beliefs when it "has looked for" new tools that could be useful for solving new problems. This is why we suppose that standard model of CSR in a bit wrong way presents its story about origin of religious beliefs as a by-product of natural selection. It is worth to bear in mind particular, perhaps the same in different cultures and regions, functions that have been played by religious beliefs, rituals, and religions. Perhaps some religious systems were focused more on other fields than other religious systems. However, it seems that probably majority of them was oriented on solving psychological and social problems. Consequently, they were and are also today adaptive at least for the clergy whose can effectively accumulates material resources and prestige by reference to the unique theistic license in morality and metaphysics.

Even in the current secularized societies in which religious systems do not work as a group-level adaptation, they can effectively work as individual-level adaptation. We mean psychological coping and stress reduction. In this matter we find unbroken continuity from the Paleolithic shamanistic rituals to the current positive impact of religious beliefs and practices for psychical health. We suppose that this adaptive explanation works better than the by-product hypothesis. Religious beliefs usually were and are associated with particular pragmatic functions and it seems improbable that their evolution is a domain of not designed evolutionary side-effect. We accept the point of view of Rappaport and Corbally that suggest that it is possible to interpret as adaptation all these mechanisms that have served for evolution and enhancing sociability [25. p. 99]. There is no doubt that religious beliefs were very useful and perhaps necessary in the natural history of humans for the evolution of ultra-sociality and cooperation.

\section{Conclusion}

We are aware that there are possible different explanations of the origin and nature of religious beliefs among cognitive and evolutionary studies of religion. Beside these two approaches we find 
many others, more traditional ways of - rather understanding than interpreting - religious beliefs. It seems that perhaps the more useful way it would be some kind of combination of these more scientific with more humanistic and social ways of analyzing of religious beliefs.

I wanted to show that the cognitive approach towards the study of religion is a good and promising way. However, I think that this approach is too narrow and it would be better to use some basic concepts of CSR as a starting point for further, not cognitive explanation of religious. I suppose that religious beliefs should be explained also by their pragmatic functions because they were probably always associated with some pragmatic purposes at the group or at the individual levels. To develop further this last approach, the good explanatory way is the evolutionary study of religion.

\section{Acknowledgement}

I would like to thank William J. Shoemaker (University of Connecticut, ret.), Daniel Lim (Renmin University) and Melanie McConnell (University of Edinburgh) for all useful comments. I thank Jay Feierman (University of New Mexico, ret.) for his consultations and explanations referred to biological and evolutionary issues.

\section{References}

1. Barrett, J.L. Cognitive Science of Religion: Looking Back, Looking Forward. Journal for the Scientific Study of Religion, vol. 50 (2), 2011.

2. Barrett, J.L. Cognitive Science of Religion: What is it and why is it? Religion Compass, vol. 1 (6), 2007.

3. Barrett, J.L. Why Would Anyone Believe in God? Cognitive Science of Religion Series. Walnut Creek: Calif. and Oxford, 2004.

4. Barrett, J.L., Jarvinen, M. J. Evolutionary byproducts and imago Dei. In. M. Jeeves (ed.). The emergence of personhood: A quantum leap? Grand Rapids, MI: Eerdmans, 2015, pp. 163-183.

5. Blume, M. The Reproductive Benefits of Religious Affiliation. In. E. Voland, W. Schiefenhovel (eds.). The biological evolution of religious mind and behavior. Springer: Berlin Heidelberg, 2009.

6. Boyer P. The Naturalness of Religious Ideas: A Cognitive Theory of Religion. Berkeley-London, 1994.

7. Clark, K.J. Trusting intuitions? Book symposium: a natural history of natural theology by Helen de Cruz and Johan de Smedt, Religion, Brain \& Behavior, 2016.

8. Crivelli, C., Russell, J. A., Jarillo, S., Fernández-Dols, J.-M. The fear gasping face as a threat display in a Melanesian society. Proceedings of the National Academy of Sciences of the United States of America, published ahead of print October 17, 2016.

9. De Cruz, H., Smedt, J. De. A natural history of natural theology. MIT, 2015.

10. Diamond, J. The Third Chimpanzee: The Evolution and Future of the Human Animal. Hutchinson Radius, 1991.

11. Eyghen, H., Van. Religious Belief is Not Natural. Why Cognitive Science of Religion Does Not Show That Religious Belief is Trustworthy. Studia Humana, vol. 5:4, 2016, pp. 35-45.

12. Feierman, J. R. How Some Major Components of Religion Could Have Evolved by Natural Selection? In. E. Voland, W. Schiefenhovel (eds.). The biological evolution of religious mind and behavior. Springer: Berlin Heidelberg, 2009.

13. Feierman, J. R. Religion's Possible Role in Facilitating Eusocial Human Societies. A Behavioral Biology (Ethological) Perspective. Studia Humana, Vol. 5:4, 2016, pp. 5-34.

14. Futuyma, D. J. Evolution. Sinauer Associates, INC.: Massachusetts, 2006.

15. Garson, J. The biological mind. A philosophical introduction. Routledge: New York, 2015. 
16. Jarnefelt, E., Ford Canfield, C., Kelemen, D. The divided mind of a disbeliever: Intuitive beliefs about nature as purposefully created among different groups of non-religious adults. Cognition, 140, 2015, pp. 72-88.

17. Kahane, G. Evolutionary Debunking Arguments. Noûs, vol. 45:1, 2011.

18. Kelemen, D., Rottman, J., Seston, R. Professional physical scientists display tenacious teleological tendencies. Purpose-based reasoning as a cognitive default. Journal of Experimental Psychology: General, 142(4), 2013, pp. 1074-1083.

19. Kelemen, D., Seston, R., Georges, L. The designing mind: Children's reasoning about intended function and artifact structure. Journal of Cognition and Development, 4, 2012, pp. 439-453.

20. Lewontin, R. C. The analysis of variance and the analysis of causes. American Journal of Human Genetics, 26, 1974.

21. McCauley, R. N. Why Religion is Natural and Science Is Not. Oxford University Press: Oxford, 2011.

22. Norenzayan, A. Big Gods: How Religion Transformed Cooperation and Conflict. Princeton University Press, 2013.

23. Peoples, H.C., Duda, P., Marlowe, F. W. Hunter-Gatherers and the Origins of Religion. Human Nature, May 2016.

24. Purzycki, B.G., Sosis, R. The Religious System as Adaptive: Cognitive Flexibility, Public Displays, and Acceptance. In. E. Voland, W. Schiefenhovel (eds.). The biological evolution of religious mind and behavior. Springer: Berlin Heidelberg, 2009.

25. Rappaport, M. B., Corbally, Ch. Matrix thinking: an adaptation at the foundation of human science, religion, and art. Zygon, vol. 50, no. 1, March 2015.

26. Rottman, J., Kelemen, D. Is there such a thing as a Christian child? Evidence of religious beliefs in early childhood. In. P. McNamara, W. Wildman (eds.). Science and the world's religions: Persons and Groups. Praeger Press: Santa Barbara, CA, 2012.

27. Sanderson, S. K. Adaptation, evolution, and religion. Religion, 38, 2008.

28. Sosis, R. The adaptationist-byproduct debate on the evolution of religion: five misunderstandings of the adaptationist program. Journal of Cognition and Culture, 9, 2009.

29. Stark, R. Rational Choice Theories of Religion. Agora, 2, 1, 1994.

30. Sterelny, K., Joyce, R., Calcott, B., Fraser B. (eds.). Cooperation and its evolution. MIT: Cambridge MA, 2013.

31. Szocik, K., Herian, R. Evolutionary roots of the property rights; the natural and cultural nature of human cooperation. The Heythrop Journal, 2016.

32. Szocik, K., Szyja, A. Poland: A Dark Side of Church Cultural Policy. Studia Humana, vol. 4, Issue 4, December 2015.

33. Szocik, K., Walden, P. L. Why atheism is more natural than religion. Studia Religiologica, 48 (4), 2015.

34. Trivers, R. L. The Evolution of Reciprocal Altruism. The Quarterly Review of Biology, vol. 46, no. 1 (Mar.), 1971.

35. Voland, E. Evaluating the Evolutionary Status of Religiosity and Religiousness. In. E. Voland, W. Schiefenhovel (eds.). The biological evolution of religious mind and behavior. Springer: Berlin Heidelberg, 2009.

36. Wilson, D. S. Darwin's Cathedral. Evolution, religion, and the nature of society. The University of Chicago Press: Chicago London, 2002. 